\title{
Sexual risk taking in adolescence: examining negative gender beliefs
}

\author{
Suzanne Robinson* \\ *This manuscript was prepared under the supervision of Professor Karl Hennig, \\ Department of Psychology, College of Social and Applied Human Sciences, \\ University of Guelph, Guelph, Ontario, Canada
}

\begin{abstract}
Sexual risk taking behaviour carries a number of aversive outcomes including HIV infection, STIs and unplanned pregnancies. Past research has shown adolescents in particular are at a high risk for these negative consequences. This study examines how negative gender beliefs operate to predict sexual risk taking in later adolescence. Participants were 164 adolescents that completed 2 questionnaires over 2 years. Past research has suggested sexual risk taking behaviour is determined by multiple systems of influence. Therefore, additional demographic and contextual variables were included in data analysis. Results suggest that the single best predictor of future sexual risk taking is past sexual risk taking $F(10,170)=.54, \quad p<.001$. Additionally, high levels of drug use, $F(10,170)=.25, p<.001$ and low acceptance of interpersonal violence, $F(10,170)=-.19, p<.05$ were found to predict sexual risk taking in later adolescence. The findings have significant implications on intervention and prevention methods aimed at adolescent sexual health.
\end{abstract}

$\mathrm{B}$ eginning in the 1970s with the increasing awareness of HIV and AIDS, there has been a growing body of research on sexual risk taking. Sexual risk taking has been defined in the past as unprotected sex, sex with multiple partners and early onset of sexual activity [1, 2, 3, 4]. These behaviours carry an increased risk of HIV infections, STIs and unplanned pregnancies. The impact of these behaviours can bring about serious lifelong consequences, and the cost to both the individual and society can be staggering. Adolescents in particular have been found to be at high risk for sexual risk taking behaviours and the negative consequences including infection of HIV, other sexually transmitted infections (STIs) and unintentional pregnancies $[1,5,6]$.

In 2005, approximately $48 \%$ of adolescents participating in the national Youth Risk Behaviour Survey reported being sexually active [7]. Sexuality can be a normal aspect of adolescent development but the rates of unprotected sex and sex with multiple partners reported were alarmingly high. Of the students who reported being sexually active, $39 \%$ did not use condoms as last intercourse [7]. Failure to use condoms consistently and properly puts adolescents at a much greater risk of STI infections and unplanned pregnancies. In addition to consistent condom use and abstinence, monogamy has proven to reduce the risk of HIV infections and STIs when paired with frequent screenings. Yet, $10 \%$ of $9^{\text {th }}$ grade students and $21 \%$ of $12^{\text {th }}$ grade students reported four or more sexual partners [7].
Early onset of sexuality is also a concern. Adolescents experiencing early sexual debut are not only at a greater risk for dating violence [8] but also experience an increased likelihood of unintended pregnancy, HIV infections and other STIs [9]. Unfortunately, the national Grunbaum's 2002 study found that $34 \%$ of the adolescents reported having intercourse before reaching 15 years old [10].

Engaging in these risky sexual behaviours has clear negative repercussions for adolescents. An estimated half of STIs diagnosed annually in the United States occur among people under the age of 25 [11]. Approximately 9.1 million teenagers are infected with one or more STIs each year [12] across the United States. Not only that, but nearly a million 15-19 year olds became pregnant in the United States and 40,000 in Canada in 2001 alone [13].

\section{Negative Gender Beliefs}

Researchers are understandably motivated to gain a better understanding of factors that contribute to sexual risk taking behaviours. One variable that has been examined in past studies is a gender belief system. A gender belief system, or gender schema has been defined as beliefs, cognitions and ideas related to male-female differences and to masculinity and femininity [14]. These beliefs influence the way people, situations and events are interpreted and guide our behaviour [15]. Past research has found puberty brings about an intensification of gender schemas and expectations [16, 17, 
18, 19], suggesting this study's focus on adolescents may be particularly relevant.

Gender beliefs are generally seen as a set of cognitions that are multidimensional [15, 20, 21]. Beliefs can be multidimensional in the sense that they may vary according to the domain or context (ie. beliefs about gender roles in the workforce vs. in the home or beliefs about the familiar or unfamiliar person). It stands to reason that these different, domain-specific beliefs may relate to sexual risk taking in unique and individual ways. This study focuses on two types of negative gender beliefs: adversarial sexual beliefs and acceptance of interpersonal violence. More generally, negative gender beliefs involve endorsement of social norms and scripts that afford men more power than women. These beliefs emphasize an unequal division of power and stereotypical norms about masculinity [20]. Adversarial sexual beliefs and acceptance of interpersonal violence are conceptualized here as two aspects of a gender belief system that may relate to sexual behaviours in different ways.

It has been suggested that negative gender beliefs may be relevant to our understanding of sexual decision-making and risk taking. As Shearer et. al's study reasoned, when these beliefs are accepted, there is pressure to embody stereotypical, traditional gender roles. For men this may involve taking on the role of 'sexual adventurer' while women may drift towards leaving important sexual decisions up to their partners [20]. A number of recent studies support the link between different dimensions of negative gender beliefs and a variety of risky sexual behaviours. For instance, Shearer found that gender-based family role attitudes was related to risky condom related beliefs within a sample of male college students [20]. Other studies have found that males with traditional gender ideologies report more sexual infidelity, casual sex partners, unprotected sex and negative attitudes towards condoms [22-24].

\section{Demographic and Contextual Variables}

It is clear from past research that gender beliefs do not independently predict sexual risk taking in its entirety. Instead, these beliefs function within a larger system involving contextual and demographic variables. It is important to note that sexual decisions are multifaceted and depend on a multitude of factors. This multisystemic approach to explaining sexual risk taking behaviour has been suggested in the past but is rarely used in research [25]. With this in mind, I will be including additional variables in my analysis.

A number of demographic and contextual variables are associated with sexual risk taking behaviours, including gender, age, family structure, parental education and delinquency.

Past research suggest that both genders are at risk for engaging in sexual risk taking, yet males and females tend to exhibit different risky behaviours. Adolescent girls are more likely to forgo condom use with partners and males tend to report more sexual partners [26-29]. Additionally, age has consistently been associated with sexual behaviour, with older adolescents engaging in more sexual risk taking [1, 25, 27]. This trend continues into adulthood, with older single adults reported less frequent condom use than younger single adults [30].

Research on family structure suggests that living with two parents may protect adolescents from engaging in risky sexual behavior [1, 24, 31]. For example, Raefelli [1] found that living in a single parent home was associated with higher levels of sexual risk taking behaviours.

Additionally, Raefelli's study found mothers who completed high school or GED were less likely to have sexual risk taking adolescents. However, this relationship was only marginally significant and findings have been largely inconclusive in this area [1].

Research has also begun to suggest a relationship between sexual risk taking and delinquent behaviour, alcohol use and substance use. For instance, Devine [32] found general delinquency to relate to number of sexual partners among males and females. Further, drug use and alcohol consumption have been found to greatly increase the risk of engaging in unsafe sexual practices [24, 29, 33, 34, 36] including early onset and sex without protection.

\section{CURRENT StUdY}

With the staggering negative consequences risky sexual behaviour can have on a person and society, it is understandably important to continue research is this area. Despite many years of research, the mechanisms that lead to risk-taking behavior are still poorly understood.

A comprehensive literature review on sexual risk taking found that research has been largely cross-sectional rather than longitudinal [25]. Large sample cross sectional studies have allowed researchers to identify variables related to sexual risk taking but the direction of the relationship remains somewhat unclear [25]. To better understand influencing factors of risk behaviour, Kotchick [25] recommends the use of longitudinal data. With longitudinal rather than cross sectional data, we are better able to determine whether or not any factors can actually predict sexual risk taking in later adolescence.

The aim of this study was to examine how negative gender beliefs assessed in grade 9 and 10 operate to predict sexual risk taking later in adolescence. Consistent with past research, it was hypothesized that adolescents exhibiting high levels negative gender beliefs would be more likely to engage in sexual risk taking. Furthermore, considering multiple systems of influence is important to our understanding of sexual risk taking. With this in mind, contextual and demographic variables were examined. 
Table 1: Scale Descriptives

\begin{tabular}{|c|c|c|c|}
\hline Variable & $N$ & Mean $(S D)$ & Percentage \\
\hline \multicolumn{4}{|l|}{ Predictor Variables (Year 1) } \\
\hline Adversarial Sexual Beliefs & 187 & $2.03(.447)$ & \\
\hline Acceptance of Interpers. Violence & 187 & $1.47(.413)$ & \\
\hline \multicolumn{4}{|l|}{ Sexual Behaviour (Year 2) } \\
\hline Sexual Risk Taking Composite & 187 & $0.91(1.07)$ & \\
\hline No. of sex partners last year ${ }^{3}$ & & $1.87(1.22)$ & \\
\hline Substance use with sex $\left(\%\right.$ yes) ${ }^{a}$ & & & .41 \\
\hline Sex Before 15 (\% yes) & 144 & & .49 \\
\hline Infrequent condom use (\% yes) ${ }^{a}$ & & & .16 \\
\hline
\end{tabular}

\section{METHODS}

\section{Participants}

105 (males $=51$, females $=54$ ) early adolescents (average age $=15.4$ years, $\mathrm{SD}=.79$ ) and a self-nominated same-sex friend were recruited largely from Grades 9/10 after responding to flyers handed out in their classrooms (total $\mathrm{N}=$ 210). High schools were located in rural Nova Scotia, Eastern Canada. Upon parental consent each participant completed a questionnaire package and was reimbursed \$5 for participating. In the following year, participants were contacted again and asked to complete a follow-up questionnaire. Upon completion of the second questionnaire package, participants were reimbursed \$10. 164 participants (males $=71$, females $=93 ; M=15.32, S D=.87$ years of age) were available in Year 2 to complete the follow-up questionnaire package. Data analysis involved only participants who completed questionnaires in both Year 1 and Year 2.

\section{Measures}

Demographics. Participants provided information regarding age, gender and family structure at time 1. Family structure involves the relationship between parents (ie. divorced, separated, remarried, living with someone, still together). Sixty-six percent of households included both biological parents, 21\% were single parent households and 5\% included a mother and partner who was not the child's biological parent.

Sexual risk-taking. Following Raefelli's study [1], a composite variable was created to assess degree of sexual risk taking. Four relevant behaviours were assessed: early sexual onset ( $1=$ before age $15,0=15$ yrs or later or never had sex), condom use (1= never or rarely use condoms, $0=$ always use condoms), drug and alcohol use during intercourse ( $1=$ sometimes or always use drugs and alcohol, $0=$ never use drugs or alcohol) and multiple partners (2 or more partners in the last 12 months). Participants received a sexual risk taking score between 0 (no risk, never had sex) to 4 (high risk, had sex before 15, rarely or never use condoms, often uses drugs and alcohol before intercourse and 2 or more partners in the last 12 months).

Negative gender beliefs. Attitudes towards adversarial sexual beliefs and acceptance of interpersonal violence were measured at Time 1 . Negative gender beliefs and expectations are measured with these two subscales from Burt's gender attitudes scale [37] and Foshee et al.'s work [38]. 19 items were included and Responses were scored on a 4-point likert scale ranging from 1 (strongly agree) to 4 (strongly disagree). Scale reliability in the current sample was .837, with adversarial gender belief subscale reliability of .707 and acceptance of interpersonal violence had a reliability of .814 .

Delinquency, Alcohol Consumption and Drug Use were assessed with items from the National Youth Survey [39]. Delinquency measures acts ranging from minor offences (e.g., skipping school) to more serious felonies (e.g., theft exceeding \$50). Alcohol consumption was measured by frequency of drinking and frequency of binge drinking (5 or more drinks within a couple of hours) in the last 30 days. Drug use in the last year involved marijuana and other substances including ecstasy, cocaine and sniffing glue. All individual behavioural indices were standardized and summed to create composite scores for delinquency, alcohol use and drug use. These three variables were measured at Time 1.

\section{Data Analysis Plan}

Data analysis began with zero order correlations to examine associations among variables. Following the correlations, a sequence of regression models involving the sexual risk taking composite was conducted to predict sexual risk taking in Year 2. Variables were entered into the regression model in four steps: (1) participant demographics (age, gender), parental characteristics (family status), (2) sexual risk taking in Year 1 (3) gender belief scales and delinquency variables (substance abuse, antisocial behaviours).

\section{RESULTS}

\section{Sample Descriptives}

In Year 1, 44.5\% of participants (those who had completed questionnaires for Year 1 and Year 2) had begun sexual activity. In the following year, the proportion of sexually active participants increased to 55.5\%. Of those who reported being sexually active in Year 2, 16\% reported infrequent condom use, $50 \%$ had multiple partners in the last year and $41 \%$ frequently or always used alcohol or drugs during intercourse. Refer to Table 1 for details on sexual risk taking behaviours.

When considering sexual risk taking behaviours as a composite, the majority of participants reported relatively low levels of sexual risk taking, with $64 \%$ and $48 \%$ receiving 
Table 2: Intercorrelations Among Scales

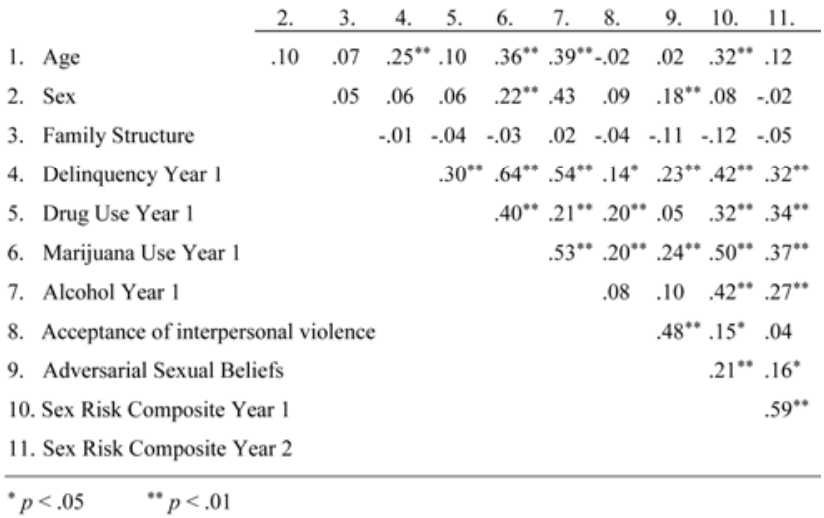

a risk-taking score of 0 (no sexual risk taking) in Years 1 and 2 , respectively. Participants received a score of 0 because they had not yet begun sexual involvement or they reported less than two partners, consistent condom use and no substance use during intercourse. High sexual risk taking (composite scores of 3 and 4) was reported among 17\% and $11 \%$ of adolescents in Year 1 and 2 respectively. These results suggest that while sexual onset increases over years 1 to 2, sexual risk taking does not. Comparing Year 1 and 2 composite scores with a paired samples $\mathrm{T}$ test revealed slight changes in sexual risk taking. The difference in composite scores for Year $1(M=1.04, S D=1.36)$ and Year $2(M=.918$, $S D=1.07)$ conditions; $t(187)=1.48, p=.141$ proved to be not significant.

\section{Primary Analyses}

Zero-order correlations among variables are shown in Table 2. The sexual risk taking composition at Year 2 was significantly correlated with five of the study variables. Among the demographic variables, no variables showed significant correlations with sexual risk taking in Year 2. However, all delinquency variables including drug use, marijuana use, alcohol use and general antisocial behaviour were positively associated with sexual risk taking. Adversarial sexual beliefs were significantly associated with sexual risk taking behaviour, but acceptance of interpersonal violence was not significantly associated with sexual behaviour. The strongest correlation with sexual risk taking at Year 2 was sexual risk taking behaviour in Year 1.

\section{Longitudinal Prediction of Sexual Risk Taking}

Hierarchical regressions were used to develop a model for predicting sexual risk taking in Year 2 (see Table 3). Age, gender, and family structure were entered at Step 1, and given the strong association between Time 1 and 2 outcome behavior, sexual risk-taking was entered at Step 2 as a control. Variables of predictive interest were entered at Step 3 , including substances (marijuana, alcohol, \& hard drug use), delinquency, and negative gender beliefs.
Results indicated that predictor variables added significant variance to predicting sexual risk-taking at Year 2 , beyond demographic variables and Year 1 sexual risktaking. Hard drug use emerged as an independent predictor of Year 2 sexual risk-taking. Acceptance of interpersonal violence, while significant, was very low and in the opposite direction. Together with the null zero-order correlation is a somewhat spurious finding.

In sum, inconsistent with predictions, acceptance of interpersonal violence in early adolescence was not a robust predictor of sexual risk-taking in Year 2, although drug use was.

\section{DISCUSSION}

This study's aim was to gain a better understanding of predictive factors for sexual risk taking in adolescence. In many ways, these results build and expand upon past research. Certain findings, however, emphasize areas in need of further exploration.

Results from the sexual risk taking composite indicate that the best predictor of future behaviour is past behaviour. In this study, sexual risk taking measured in Year 1 was a significant indicator of whether youth will engage in risky sexual practices in the upcoming year. These findings are reasonable when we consider the relatively short amount of time in between data collection periods (approximately one year).

When past sexual risk taking and demographic variables were controlled for, drug use significantly predicted sexual risk taking. Reported drug use had a significant positive effect on risky sexual behaviours. Marijuana use, alcohol use and general delinquency showed strong correlations with sexual behaviour in primary analyses yet this effect diminished in the regression models. This demonstrated relationship among substance use and delinquency echoes past research, although alcohol and marijuana use were expected to play a more significant role.

Results for negative gender beliefs were less consistent with past research than anticipated. Prior research led us to predict that acceptance of interpersonal violence and endorsement of adversarial sexual beliefs would predict higher levels of sexual risk taking. Endorsement of adversarial sexual beliefs failed to predict sexual risk taking, although there was a positive significant correlation with sexual risk taking in initial bivariate correlations. While acceptance of interpersonal violence significantly predicted sexual risk taking, the negative direction of influence seems counterintuitive. Youth who exhibit lower acceptance of interpersonal violence were more likely to engage in unsafe sexual practices. Past research has found the opposite to be true, with significant correlations among partner violence, traditional gender ideologies and unprotected sex [22]. Perhaps acceptance of interpersonal violence is a reflection of wide spread traditional and conservative views. It could be 
Table 3: Hierarchical Regression Analyses Predicting Sexual Risk-Taking in Year 2

\begin{tabular}{|c|c|c|c|c|}
\hline Variable & & $\Delta R^{2}$ & $F$ change & $\beta$ \\
\hline Step 1. & Age & .03 & .98 & -.074 \\
\hline & Gender & & & -.090 \\
\hline & Family Structure & & & .025 \\
\hline Step 2. & Sexual Risk-Taking Year 1 & .39 & $23.63^{* *}$ & $.54^{* * *}$ \\
\hline Step 3. & Alcohol & .05 & $12.18^{* * *}$ & .045 \\
\hline & Marijuana & & & .053 \\
\hline & Hard Drugs & & & $.25 * * *$ \\
\hline & Delinquency & & & -.06 \\
\hline & Acceptance of interpersonal violence & & & $-.19 * *$ \\
\hline & Adversarial gender beliefs & & & .11 \\
\hline
\end{tabular}

reasoned that adolescents endorsing these conservative views would not engage in premarital sex or promiscuity. It would be unwise to draw this conclusion without including a measure of general conservativeness in future research as the significance level was not robust.

Additionally, descriptive statistics indicate a positive change in sexual risk taking as adolescents age. Data showed that while sexual onset increases over years 1 to 2 , risk taking behaviours as a percentage drops. This suggests some greater personal responsibility is taking place as participants grow older. An increase in safe sexual practices with age is inconsistent with past research [1, 27, 25, 30] but certainly a positive finding in regards to adolescent sexual health and safety.

\section{Limitations and Future Research}

An explanation for the disparity between past research and the current findings on gender beliefs could involve the measurement of these schemas. Issues about how to best measure gender identity, gender roles and gender stereotypes have been documented consistently in past research. Many different approaches have been taken including assessing gender knowledge [40] self-reported masculine and feminine personality traits [14], personality measures and a number of scales involving stereotype attitudes [20, 22, 38, 37, 38, 41]. One study found that no single method of measuring gender beliefs dominates literature [42]. This study involved a narrow and domain specific view of gender cognitions and a more expansive approach may prove to be valuable. Alternatively, future studies could include a larger number of gender belief components through the use of additional scales.

The power of the present study was also limited by its inability to explore ethnic variation (over 93\% Caucasian). Past studies have found significant ethnic variation among sexual risk taking [43] and future studies in this area would be valuable in further testing the generalizability of these findings.

Next, self-report questionnaires always carry a certain level of social desirability and/or inaccuracy, particularly when sensitive subjects like sexual behaviour are involved. While past research has shown impressive honesty among adolescents completing sexual behaviour questionnaires [44], future research would benefit from including more objective measures. The present study was also limited in its assessment of the samples demographics and contextual variables. A more detailed analysis of possible contributing factors (e.g maternal education and socio-economic status) would have provided more insight into the findings.

\section{Implications and Conclusions}

Understanding predictors of sexual risk taking in adolescence has great implications for prevention and intervention programs. When we have a better understanding of the factors affecting sexual decision making, we are better able to shape prevention and intervention programs that suit's the specific needs of adolescents. More specifically, this study's findings explored the importance of incorporating gender equality discussions in adolescent sexual health programs. While the current study's results regarding gender beliefs are not wholly conclusive, interventions that promote less traditional gender role ideologies should continue to be considered in addressing sexual risk taking. These results do, however, cement the notion that substance use and delinquency are integrally linked with sexual risk taking. With this in mind, intervention programs that target substance abuse may have twofold benefits - a decrease in substance abuse and an increase in safe sexual practices.

\section{REFERENCES}

1. Raffaelli, M. \& Crockett, L. (2003). Sexual risk taking in adolescence: the role of self regulation and attraction to risk. Developmental Psychology 39:6, pp. 1036-1046

2. Baumeister, L. M., Flores, E., \& Marin, B. (1995). Sex information given to Latina adolescents by parents. Health Education Research, 10, 233-239.

3. Caminis, A., Henrich, C., Ruchkin, V., Schwab-Stone, M., Martin, A. (2007). Psychosocial predictors of sexual initiation and high-risk sexual behaviors in early adolescence. Child and Adolescent Psychiatry and Mental Health, 1 (14), 1-12.

4. Rosenthal, D., Moore, S. \& Flynn, I. (1991). Adolescent self-efficacy, self-esteem and sexual risk-taking. Journal of Community and Applied Social Psychology, 1 (2), 77.

5. Eng, R. \& Butler, W. (1996). The Hidden Epidemic: Confronting Sexually Transmitted Diseases. Washington, D.C.: National Academy Press.

6. U.S. Department of Health and Human Services. 2004. Guidelines for Treatment of Sexually Transmitted Diseases, United States, 2004. MMMR Weekly 53, 1-29.

7. Eaton, D., Kann, L., Kinche, S., Shanklin, S., Ross, J., Hawins, J., Harris, W., Lowry, R., McManus, T., Chyen, D., Lim, C., Brener, N. \& Wechsler, H. (2008). Youth Risk Behavior Surveillance - United States, 2007. 
Morbidity and Mortality Weekly Report Surveillance Summaries, 57(SS04), 1-131.

8. Makepeace, J.M. (1987). Social factor and victimoffender differences in courtship violence. Family relations, 36, 87-91.

9. Crockett, L., Chopak, J., Bingham, R. \& Vicary, J. (1996). Timing of first sexual intercourse: The role of social control, social learning and problem behaviour. Journal of Youth and Adolescence, 25:1, 89-111.

10. Grunbaum, J.A., Kann, L., Kinchen, S.A., Williams, B., Ross, J.G., Lowry, R. \& Kolbe, L. (2002). Youth risk behaviour surveillance United States, 2001. Morbidity and Morality Weekly Report, 51 (SS-4).

11. Centers for Disease Control and Prevention. Youth online: comprehensive results. Available at: http://apps.nccd.cdc.gov/yrbss/SelQuestyear.asp?cat4\&d escsexual \%20\%20Behaviors.

12. Weinstock, H., Berman, S. \& Cates, W. (2004). Sexually transmitted infections among American youth: incidence and prevalence estimates. Perspectives on Sexual and Reproductive Health, 36, 6-10.

13. Moore, K., Manlove, J., Terry-Humen, E., Williams, S., Papillo, A. R., \& Scarpa, J. (2001). Child trends: Facts at a glance 2001. Retrieved October 10 2009, from Child Trends Web site: http://www.childtrends.org/factlink.asp

14. Bem, S. (1981) Gender schema theory: A cognitive account of sex typing. Psychological Review, 88, 354364.

15. Martin, C. L. (2000). Cognitive Theories of gender development. In T. Eckes \& H. M Trautner (Eds.), The developmental social psychology of gender (pp. 91-122). Mahwah, NJ: Lawrence Erlbaum.

16. Hill, J. P. \& Lynch, M. E. (1983). The Intensification of gender-related role expectations during puberty. New Directions for Child and Adolescent Development, 106, 23-24.

17. Galambos, N. L., Almeida, D. M., \& Peterson, A. C. (1990). Masculinity, femininity and sex role attitudes in early adolescence: Exploring gender intensification. Child Development, 61, 1905-1914.

18. Crouter, A., Manke, B. A, \& McHale, S. M. (1995) The family context of gender intensification in early adolescence. Child Development, 66, 317-329.

19. Jacobs, J. E., Lanza, S., Osgood, D. W., Eccles, J. S., \& Wigfield, A. (2002). Changes in children's selfcompetence and values: Gender and domain differences across grades one through twelve. Child Development, 73, $509-527$.

20. Shearer, C., Hosterman, S., Gillen, M. \& Lefkowitz, E. (2005). Are traditional gender role attitudes associated with risky sexual behaviour and condom related beliefs? Sex Roles Journal, 52, 311-324.
21. Huston, A. (1985). The development of sex typing: Themes from recent research. Developmental Review, 5 (1), 1-17.

22. Santana, C., Raja, A., Decker, M., La Marche, A. \& Silverman, J. (2006). Masculine gender roles associated with increased sexual risk and intimate partner violence perpetration among young adult men. Journal of Urban Health, 83, 575-585.

23. Lawrence, K., Taylor, D. Byers, E.S.(1996). Differences in men's and women's global, sexual, and ideal-sexual expressiveness and instrumentality. Sex Roles: A Journal of Research, 34 (5), 337.

24. Murnen, S.K., Wright, C. \& Kaluzny, G. (2002). If 'boys will be boys,' then girls will be victims? A metaanalytic review of the research that relates masculine ideology to sexual aggression. Sex Roles: A Journal of Research, 46 (11), 359.

25. Kotchick, B., Shaffer, A., Forehand, R. (2001). Adolescent Sexual Risk Behaviour: A Multi-System Perspective, 21, 493-519.

26. Shrier, L., Harris, S., Sternberg, M. \& Beardslee, W. (2001) Associations of depression, self-esteem and substance use with sexual risk among adolescents. Preventative Medicine, 33, 179-189.

27. Lehrer, J., Shrier, L., Gortmaker, S. \& Buka, S. (2006). Depressive symptoms as a longitudinal predictor of sexual risk behaviours among US middle and high school students. Pediatrics, 118, 189-200.

28. Overby, K. J., \& Kegeles, S. M. (1994). The impact of AIDS on an urban population of high-risk female minority adolescents: Implications for intervention. Journal of Adolescent Health, 216- 227.

29. Luster, T., \& Small, S. A. (1994). Factors associated with sexual risk-taking behaviors among adolescents. Journal of Marriage and the Family, 56, 622- 632.

30. Rottermann, M. \& McKay, A. (2009). Condom use at last sexual intercourse among unmarried, not living common-law 20- to 34-year-old Canadian young adults. Canadian Journal of Human Sexuality, 18 (3).

31. Harvey, S. M., \& Spigner, C. (1995). Factors associated with sexual behavior among adolescents: A multivariate analysis. Adolescence, 30, 253- 264.

32. Devine, D., Long, P., \& Forehand, R. (1993). A prospective study of adolescent sexual activity: Description, correlates, and predictors. Advances in Behaviour Research and Therapy, 15, 185 -209.

33. Tubman, J. G., Windle, M., \& Windle, R. C. (1996). Cumulative sexual intercourse patterns among middle adolescents: problem behavior precursors and concurrent health risk behaviors. Journal of Adolescent Health, 18, 182- 191.

34. Tapert, S., Aarons, G, Sedlar, G. \& Brown, S. (2001). Adolescent substance use and sexual risk taking. Journal of Adolescent Health, 28, 181-189. 
35. Shrier, L., Emans, S., Woods E. \& DuRant D. (1996). The association of sexual risk behaviors and problem drug behaviors in high school students. Journal of Adolescent Health 20, 377-383

36. Lowry, R., Holtzman, D., Truman, B., Kann, L., Collins, J. \& Kolbe, L. (1994). Substance Use and HIV-Related Sexual Behaviors among US High School Students: Are They Related? American Journal of Public Health, 84 (7), 1115-1110.

37. Burt, M. (1980). Cultural Myths and Supports for Rape. Journal of Personality and Social Psychology, 38, 217230

38. Foshee, V. A., Bauman, K., Arriaga, X., Helms, R., Koch, G. \& Linder, G. (1998). An evaluation of Safe Dates, an adolescent dating violence prevention program. American Journal of Public Health, 88 (1), 45.

39. Wolfe, D. A. (2002). Youth Behavior Risk Survey. Unpublished questionnaire. University of Western Ontario, London, ON.
40. Levy, G.D. \& Carter, D.B. (1989). Gender schema, gender constancy, and gender-role knowledge: The roles of cognitive factors in preschoolers' gender-role stereotype attributions. Developmental Psychology, 25 (3), 444.

41. Signorella, M. \& Liben, L. (1985). Assessing children's gender stereotyped attitudes. Psychological Documents, $15,7$.

42. Signorella, M., Bigler, R. \& Liben, L. (1993). Developmental differences in children's gender schemata about others: A meta-analytic review. Developmental Review, 13, 147-183.

43. Miller, K. S., Forehand, R., \& Kotchick, B. A. (2000). Adolescent sexual behavior in two ethnic minority samples: A multi-system perspective. Adolescence, 35, 313- 333.

44. Seigel, D., Aten, M. \& Roghmann, K. (1998). SelfReported Honesty Among Middle and High School Students Responding to a Sexual Behaviour Questionnaire. Journal of Adolescent Health, 23, 20-28. 